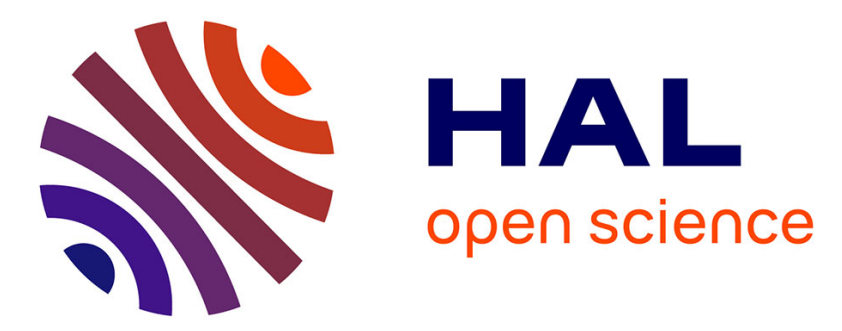

\title{
Can LED-based road studs improve vehicle control in curves at night? A driving simulator study
}

\author{
Amit Shahar, Roland Bremond, Céline Villa
}

\section{To cite this version:}

Amit Shahar, Roland Bremond, Céline Villa. Can LED-based road studs improve vehicle control in curves at night? A driving simulator study. Lighting research and technology, 2018, 50 (2), pp. 266-281. 10.1177/1477153516660146 . hal-01377739

\section{HAL Id: hal-01377739 \\ https://hal.science/hal-01377739}

Submitted on 28 May 2021

HAL is a multi-disciplinary open access archive for the deposit and dissemination of scientific research documents, whether they are published or not. The documents may come from teaching and research institutions in France or abroad, or from public or private research centers.
L'archive ouverte pluridisciplinaire HAL, est destinée au dépôt et à la diffusion de documents scientifiques de niveau recherche, publiés ou non, émanant des établissements d'enseignement et de recherche français ou étrangers, des laboratoires publics ou privés. 


\title{
Can light emitting diode-based road studs improve vehicle control in curves at night? A driving simulator study
}

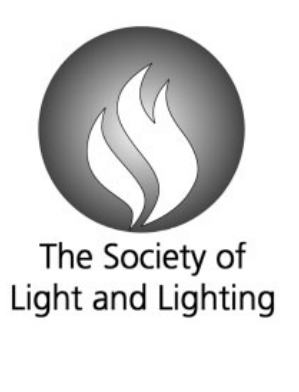

\author{
A Shahar PhD, R Brémond PhD and C Villa PhD \\ Laboratoire Exploitation, Perception, Simulateurs et Simulations, Institut \\ Français des Sciences et Technologies des Transports, de I'Aménagement \\ et des Réseaux, Cite Descartes, Champs-sur-Marne, France
}

Received 12 April 2016; Revised 13 June 2016; Accepted 27 June 2016

\begin{abstract}
Road delineation treatments enhance the ability of drivers to control their vehicle safely on winding roads. A simulator experiment compared night-time driving on a country road under three conditions: on an unlit road, on a road illuminated on curves by typical road luminaires, and on a road with an active lane delineation application, where self-luminous road studs are turned on to outline the lane and road edges as the driver approaches and passes the curves. The unlit condition induces greater lateral position variability and longer crossovers relative to the studs condition, demonstrating better lateral vehicle control in the latter. The luminaires condition induce greater lateral position variability in left curves, and longer crossovers in right curves, relative to the studs condition, which also demonstrates a better lateral vehicle control in the studs condition. At a subjective level, the participants perceived both the studs condition and the luminaires condition as safer, more comfortable and allowing better control than the unlit road. It was concluded that the tested application enhanced the ability of drivers to control the virtual car, as compared to an unlit road or road lighting.
\end{abstract}

\section{Introduction}

Efficient delineation of road space is a crucial element of a safe driving environment. The enhancement brought by painted lane markings to the road edges provides visual cues which boost the ability of drivers to predict the curvature of the road, to reduce their vehicle's lateral displacement and to appropriately adjust their position and speed to the road characteristics. As such, painted line markings have the potential to contribute to a reduction in loss of vehicle's control and runoff-road crashes and indeed, the presence of edge- and centre-lines contributes to a large

Address for correspondence: Roland Brémond, IFSTTAR, LEPSIS, Cite Descartes, 20 boulevard Newton,

77447 Champs-sur-Marne, France.

E-mail: roland.bremond@ifsttar.fr reduction of road crashes. ${ }^{1-3}$ Improvement in driver safety performance indicators, however, can best be achieved when painted lines are used in conjunction with other treatments, such as raised pavement markers, postmounted delineators and chevrons. ${ }^{4-6}$

At night, retro-reflective raised markers (such as those called 'cat's eyes') send the light from vehicle headlights back towards the driver. 'Passive' studs have been in use for many decades. In recent years, with the development of light emitting diode (LED) technology, light emitting road studs have been introduced and manufactured for commercial use. LED-based studs perform better than retro-reflective devices, as they can be seen from a greater distance and a wider range of viewing angles, as well as under conditions of poor visibility, such as in rain and fog. 
In short, they are expected to help the driver anticipate the road path in situations where cat's eyes would not be illuminated by the headlamps. Moreover, LED-based road studs may fulfil some traditional functions of road lighting, such as visual guidance, at a much lower energy cost.

However, active road studs are seldom used to delineate roadways. As a consequence, there are very few accessible statistics and other English language records documenting their use, or studies examining their impact in a controlled environment. Reports on driver performance in the presence of active road studs and on active markings application design are limited to sporadic exceptions. Among those are a few case studies published by road studs manufacturers, reporting use of active road studs on several real roads, such as on the N200 in Holland and in the A143 in England, with a subsequent dramatic drop in crash frequency or severity. Guidelines on the use of active marking for road space have been published by the Province of North Holland in the Netherlands, ${ }^{7}$ and a simulator experiment compared driver behaviour in response to active and passive road studs. ${ }^{8}$ Reed concluded that the active studs were superior at improving drivers' lateral control of their vehicle, presumably by enhancing delineation of the offside road edge, without causing drivers, particularly older ones, to proceed at higher speeds. ${ }^{8}$

\subsection{Active lane delineation}

The present study was designed to test the effects of the application of a prototype form of active road studs in curves. The idea is to highlight the shape of the curve at night before it is in the range of headlamps; thus, better vehicle control is expected compared to road markings or cat's eyes. In the following, this application is referred to as active lane delineation (ALD). Preliminary results, with 12 participants, have been presented at a conference, ${ }^{9}$ investigating vehicle control in terms of the vehicle's lateral position, and comparing the studs condition to a baseline condition. In the present paper, the experiment was pursued with 20 participants, and a new condition was added, road lighting in the curves. This condition was considered important, firstly because road lighting is also expected to improve road safety through better visual anticipation, ${ }^{10}$ secondly because self-powered road studs are now available. ${ }^{11}$ Thus, LED-based road studs can contribute to energy savings, and a direct comparison between road lighting and LED-based road studs could help the road authorities in making cost/benefit comparisons, both in terms of economic costs and power consumption.

In the proposed application, LED-based road studs fixed on winding road sections are switched on to outline the lane edges for approaching vehicles when they are detected by a sensor, $300 \mathrm{~m}$ ahead of the first stud. They are switched off behind the vehicle. The UK's passive studs colours were applied to the LED ${ }^{12}$ but reversed to suit right-hand traffic. For further road deployment, each stud would be double-ended with the right colour for each driving direction. This way, for instance, the 'right side' studs in red (circle) in Figure 1 would appear red, but they also would appear yellow for the incoming traffic. In accordance with the Dutch guidelines, ${ }^{7}$ the studs design consisted of an introductory straight road sub-section preceding the curve, the curve, and a subsequent straight road sub-section (hereafter, curve preparation, curve and curve exit).

A relatively long preparation distance was used $(286 \mathrm{~m})$ allowing for the integration of a speed reduction countermeasure that exploits the dependence of speed perception on optic flow $^{13}$ in order to influence drivers' selection of speed, ${ }^{14-16}$ with longer stud spacing farther away from the curve, which is then reduced nearer the curve (see Figure 1). This reduction 


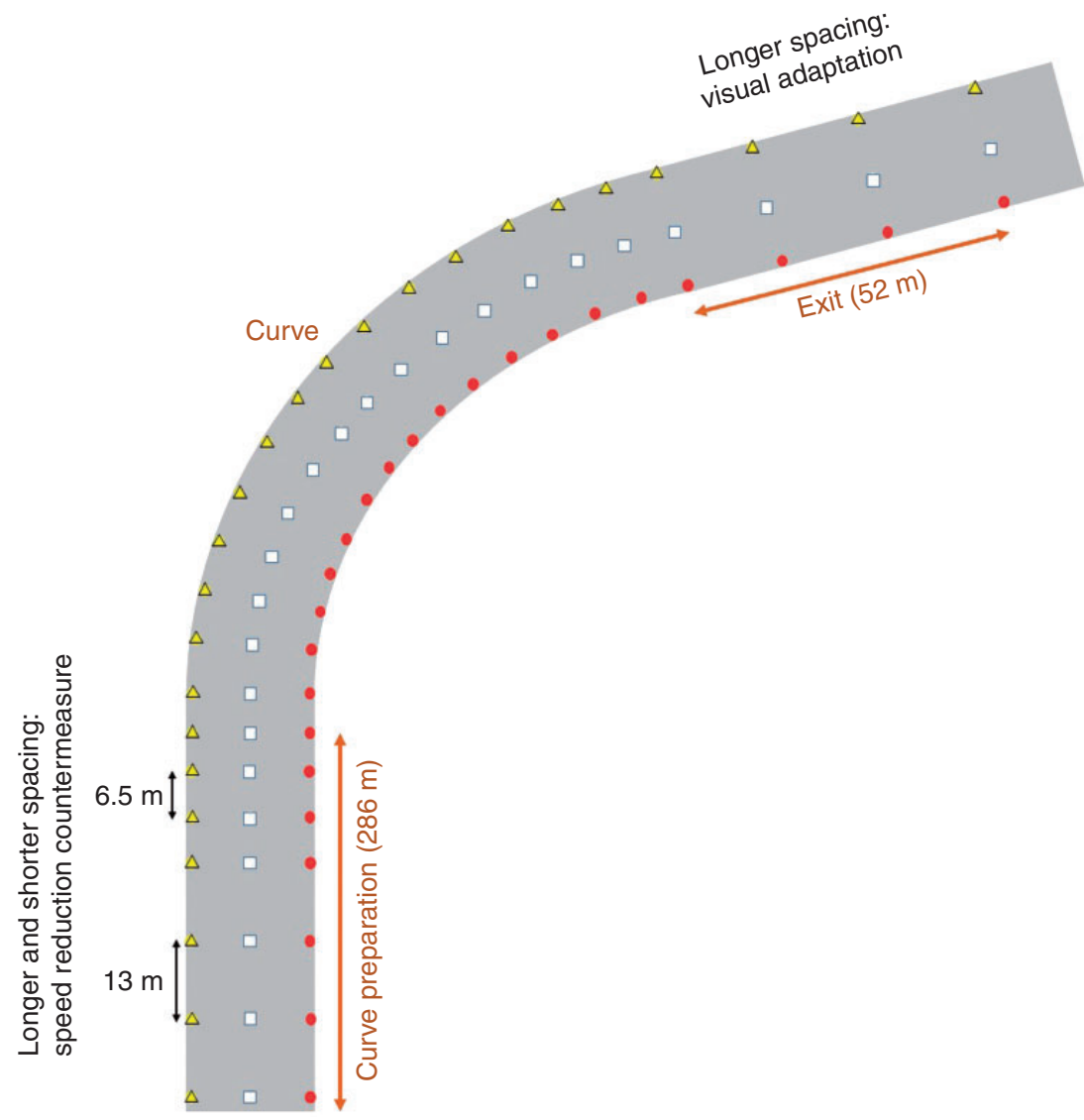

Figure 1 Presentation of the application design, including curve preparation with long and short stud spacing, a curve with short spacing and an exit with long spacing. Colours are displayed with respect to a driver making a right turn, red (circle) on the right, white dividing the road into two lanes, and yellow (triangle) on the left; for drivers coming from the top right of the Figure, the studs' colours would be reversed (available in colour in online version)

in the distance between studs in the preparatory section was thought to lead drivers to perceive their approach speeds as faster, thereby motivating them to slow down. Following Denton, ${ }^{15}$ this technique has been proven successful using both Transverse Pavement Markings ${ }^{14}$ and Chevrons. ${ }^{16}$ This speed countermeasure was expected to balance the increase in speed which occurs with most guidance systems on the road, ${ }^{17}$ including road lighting. ${ }^{18}$

Longer stud spacing at the exit from curves were thought to facilitate visual adaptation in the transition back to the unlit road. ${ }^{19}$ Under certain conditions, the shift between short and long spacing may also facilitate the identification from a distance of the beginning and the end of the curves. Figure 1 displays a studs zone incorporating a speed reduction countermeasure and a visual adaptation countermeasure.

\subsection{Driving simulation experiment}

This design was tested in a virtual environment, where the participants completed a night-time drive on the same winding 
inter-urban route under three conditions, an unlit road with only painted road markings, the same road with active studs on curves and conventional road luminaires on the curves. In all conditions, the virtual environment was tuned in such a way that the road markings were highly visible (with a luminance contrast of 10:1) everywhere in the vehicle headlamps' beam. This condition simulated a rural road with new, highly visible painting. Thus, the roadside visibility was close to what would have happened with retro-reflective (passive) studs, so that a retro-reflective studs condition was not included in the experiment.

These conditions were compared on a number of subjective criteria and objective measures of vehicle trajectory, lateral control and speed. The primary objective measure for safety was the vehicle lateral position variability. We expected that the studs would improve drivers' control of the virtual car, as indicated by the variability of the car's lateral lane positioning, at the approach to and inside the curves, as compared to the unlit road condition, but not necessarily relative to the road lighting condition. This would demonstrate that the application helps to inform the drivers to anticipate curve negotiation, by enhancing delineation of the lane and road edges. ${ }^{8}$ In addition, we predicted that drivers would travel at the fastest speeds in the road lighting condition, but given that the studs are triggered only $300 \mathrm{~m}$ before the curve preparation section and given the speed countermeasure in this condition, we did not expect significant differences in speed between the studs and the unlit conditions.

\section{Method}

\subsection{Participants}

Twenty drivers (mean age $=37$ years, $\mathrm{SD}=11$; mean license seniority $=16$ years, $\mathrm{SD}=12.5$ ), including 15 men and 5 women volunteered to participate in this study. They were recruited through advertisements that were posted via mailing lists of the French Institute of Sciences and Technology for Transport, Development and Networks (IFSTTAR). Participants spent on average 7.85 hours $(\mathrm{SD}=4.30)$ driving per week, with an annual average mileage of $5366 \mathrm{~km}$ $(\mathrm{SD}=4730)$. All of them had normal or corrected-to-normal vision: they drove the simulator with the same visual corrections they wear on the road. One participant dropped out of the experiments due to simulator sickness. The study was approved by IFSTTAR's Ethics Committee.

\subsection{Design and statistical analysis}

The main experimental factor was illumination, comparing driver performance under three conditions: active studs, unlit road and road lighting, fully counterbalanced for order. Each of these conditions consisted of a total of 16 curved and 16 straight road sections. Around each curve, three road sections were considered, thus introducing a second, 'road section' factor, in the analysis. The three road sections were:

- the straight section, $660 \mathrm{~m}$ long, terminating $286 \mathrm{~m}$ before the curve;

- the curve preparation section, $286 \mathrm{~m}$ long, starting $286 \mathrm{~m}$ before each curve and terminating at its entrance (curve preparation in Figure 1);

- the curved section, commencing at the curve's entrance and terminating $52 \mathrm{~m}$ after its exit (curve plus exit in Figure 1). This section could be $202 \mathrm{~m}$ or $452 \mathrm{~m}$ long, depending on the curve geometry (see below).

- The 16 curves consisted of eight left and eight right turns, which were of two types: four $150 \mathrm{~m}$ long with a $200 \mathrm{~m}$ radius of curvature, and four $400 \mathrm{~m}$ long with a $300 \mathrm{~m}$ radius of curvature. This was intended to increase variability in the simulated driving experience, and lower the anticipation of the road geometry. 
The key dependent variables were the speed and the standard deviation (SD) of the lateral position of the car relative to the centre of the driving lane (the SD reflects the lateral variability of the vehicle; it is a standard proxy for vehicle control). The time spent across the road's centre and nearside road edge marking lines (hereafter, centre-line and nearside edgeline) and the number of corresponding crossovers were considered as additional measures of lateral control. When applicable, these variables were analysed with $(3 \times 2)$ repeated measures analysis of variance (ANOVA) with three types of illumination (unlit, studs and luminaires) and two road sections (preparatory and curved). ANOVAs were performed on the data of right curves and the associated preparatory sections, and separately on the data of left curves and associated preparatory sections. Indeed, it was considered more relevant to separate these two analyses, as the driving pattern may be different in left and right turns. In the straight road sections, however, before the preparatory sections, the analyses gathered left and right curves together. When a significant effect was found, Tukey post-hoc tests were conducted.

Before conducting the repeated measures ANOVAs, Mauchly tests were conducted to determine whether the sphericity assumption was violated. In cases of violation, the Greenhouse-Geisser (GG) correction was used in order to adjust the degrees of freedom (the adjusted degrees of freedom are provided). For the crossover data, non-parametric tests have been conducted (Friedman and Cochran tests). The significance threshold was always set to $\mathrm{p}=0.05$.

The effect of curve radius was not investigated, as it was only intended to improve the driving simulation experience for the participants.

\subsection{Apparatus and stimuli}

The driving simulator that was used for the experiment included all the basic control devices (a steering wheel, a gear stick and accelerator, clutch and brake pedals); there was no motion platform. The simulated scene was displayed on three 47-inch full HD screens, encompassing a $108^{\circ} \times 21^{\circ}$ field of view. The central screen was a high dynamic range (HDR) monitor with improved computer graphics performance, allowing the rendering of the photometric range of existing LED-based road studs, ${ }^{20}$ together with the low-beam headlamps of oncoming vehicles, while keeping dark areas in the mesopic range. Indeed, this display device produces luminances as high as $2000 \mathrm{~cd} / \mathrm{m}^{2}$ and contrasts exceeding 20,000:1. The participants were seated $1.60 \mathrm{~m}$ from the display (see Figure 2).

The side-screens were high-quality standard monitors. Although they could not reach the same luminances as the HDR screen (either for high luminance, such as for the studs and road luminaires, or for low luminance, such as for the road surface), we do not expect this limitation to impact the driving performance: the focus of attention was on the road ahead, ${ }^{21}$ leaving the sidescreens in peripheral vision; their main purpose was to improve the self-speed perception.

The virtual road was a single carriageway with two $3.5-\mathrm{m}$ lanes, painted with regulatory discontinuous markings along the centre and the edges. It was set in a rural environment. A medium volume of traffic consisted of oncoming vehicles in the opposite lane, with at least one vehicle visible in front of the participant at any time (see Figure 2). The track consisted of four repetitions of the same combination of curves, all separated by $1000 \mathrm{~m}$ long straight roads. The curves were set in the following order: a $150 \mathrm{~m}$ long left curve with a $200 \mathrm{~m}$ radius, then a $400 \mathrm{~m}$ long left curve with a $300 \mathrm{~m}$ radius, and then the same curves to the right.

Depending on the tested conditions, the curves were also equipped with either road 


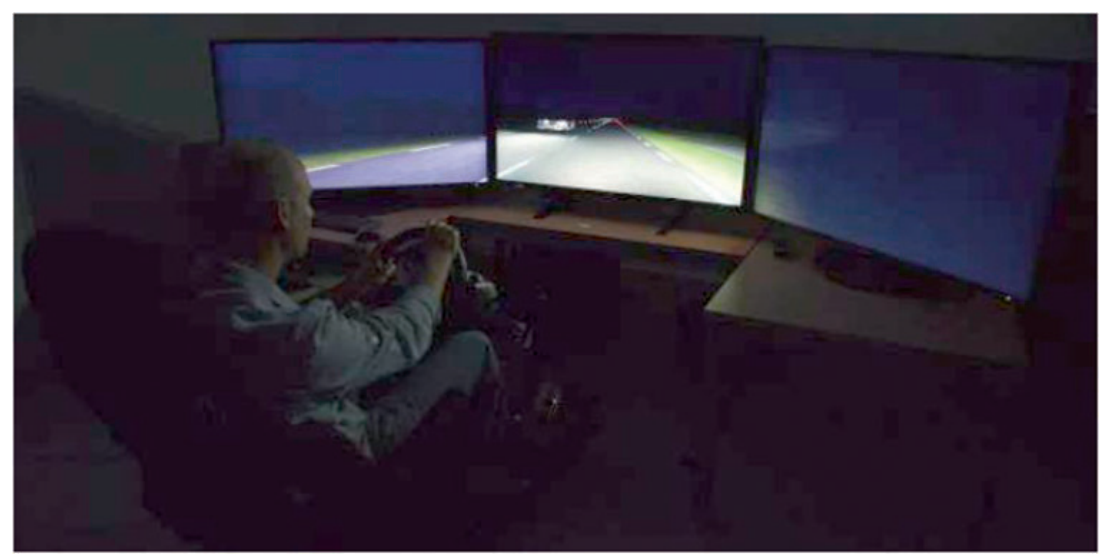

Figure 2 Driving simulator set-up

lighting luminaires, road studs along the pavement markings, or neither (see Figure 3). The scene was always illuminated by the vehicle headlamps, which had a typical range of about $60 \mathrm{~m}$. The simulated beam pattern and luminous intensity levels were tuned to be consistent with existing low-beam headlamps. The simulated road markings and pavement were tuned to create a conventional luminance contrast of 10:1, which is in the range of current retro-reflective markings. Figure 3 displays screenshots from the three experimental conditions.

\subsubsection{Dynamic ALD}

The studs began $286 \mathrm{~m}$ before the curves (see Figure 1). Red lights marked the nearside road edge, white lights marked the central line and amber lights marked the offside road edge (left edge of the road). The beam of the simulated studs spread $\pm 15^{\circ}$ horizontally and from $0^{\circ}$ to $20^{\circ}$ vertically, which is consistent with existing stud technology. The luminances of the simulated studs were measured on the screen with a Minolta LS-110 luminance photometer as 177,300 and $693 \mathrm{~cd} / \mathrm{m}^{2}$ for the red, amber and white studs, respectively, which is in the range of existing studs.
In the preparatory sections preceding the curves, $13 \mathrm{~m}$ gaps separated the studs in the first half $(143 \mathrm{~m})$, whereas $6.5 \mathrm{~m}$ gaps separated the studs in second half, just before the curve. For the $150 \mathrm{~m}$ long curves, a $202 \mathrm{~m}$ long studs section followed the preparatory section. It consisted of $6.5 \mathrm{~m}$ spaced studs fixed in the curve, followed by $13 \mathrm{~m}$ spaced studs fixed along the $52 \mathrm{~m}$ long exit. The $400 \mathrm{~m}$ long curves were divided into two subsections. The first one was $286 \mathrm{~m}$ long with $6.5 \mathrm{~m}$ spaced studs. The second was $166 \mathrm{~m}$ long and covered the remaining $114 \mathrm{~m}$ of the curve (with $6.5 \mathrm{~m}$ spaced studs) and the $52 \mathrm{~m}$ long exit (with $13 \mathrm{~m}$ long gaps).

When the virtual car had reached a distance of $300 \mathrm{~m}$ from the preparatory section, the preparatory and the next subsection (LED groups 1 and 2 in Figure 4) were both switched on simultaneously. In the longer curves, the final subsection (LED group 3 in Figure 4) was switched on as soon as the vehicle entered the preparatory section. Immediately after the vehicle passed a section, the corresponding studs were switched off. This dynamic pattern was intended to lower the energy consumption in further deployments of the system. Figure 4 displays the stud sections and subsections for the two types of curves. 
(a)

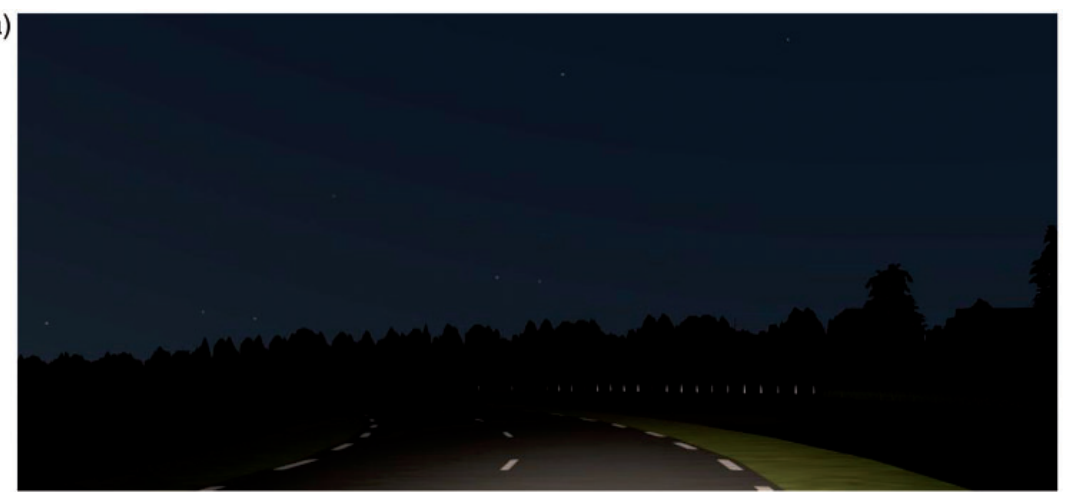

(b)

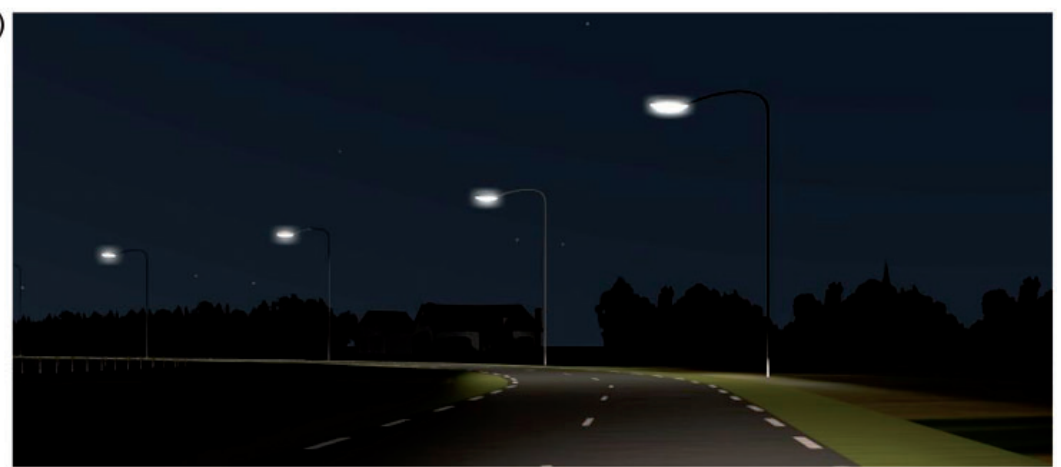

(c)

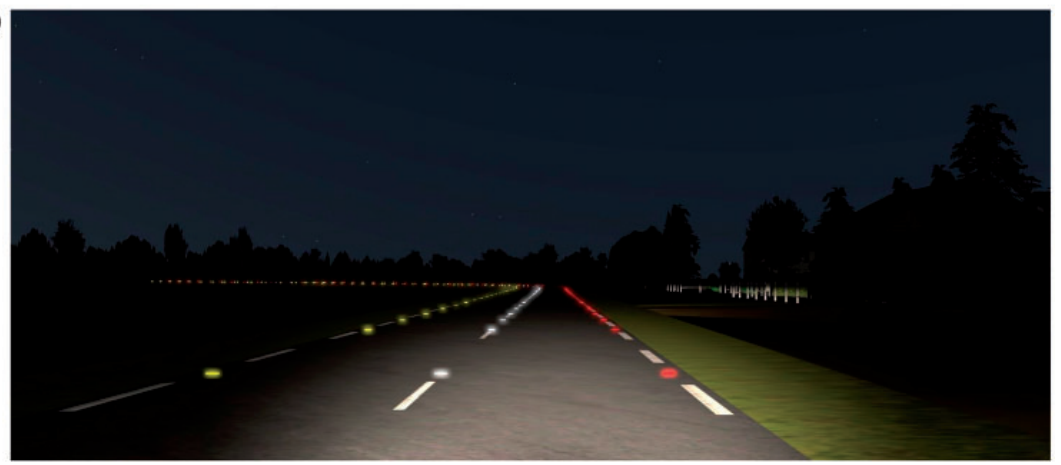

Figure 3 Screenshots of the three conditions: unlit road (top), typical luminaires (middle) and active road studs (bottom) (available in colour in online version)

\subsubsection{Road lighting}

Road lighting was installed on the same sections as those defined for the studs. The distance between the poles was $50 \mathrm{~m}$. The photometric characteristics of the lighting installation were tuned in order to comply with the European Norm EN $13201^{22}$ in terms of luminance and uniformity, using Dialux software. A mean luminance of $1.30 \mathrm{~cd} / \mathrm{m}^{2}$ was controlled with a luminance meter on the HDR screen of the driving simulator. From Dialux computations, the luminance uniformity was estimated to be around $\mathrm{U}_{0}=0.60$ (uniformity is taken as the 
(a)

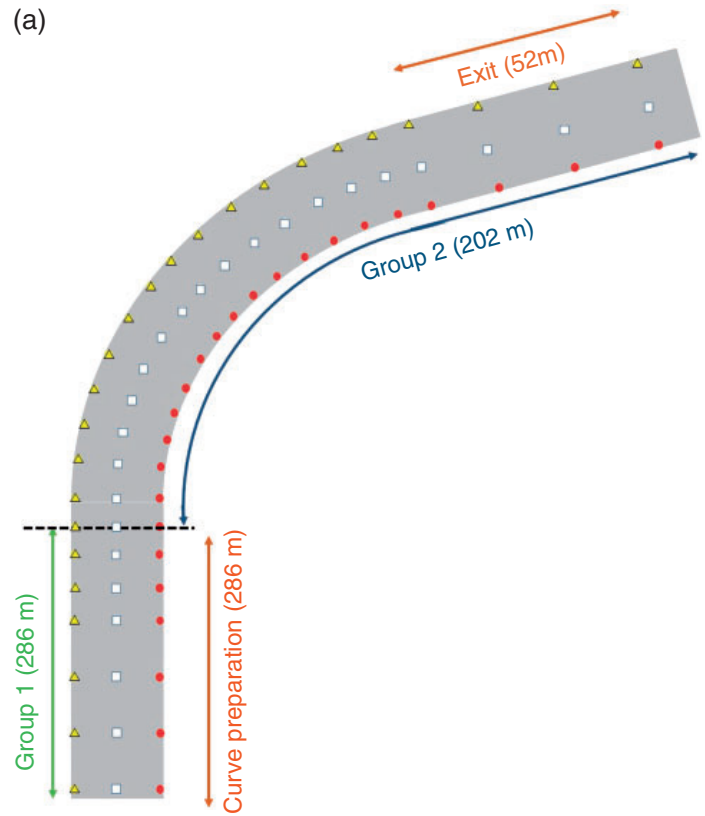

(b)

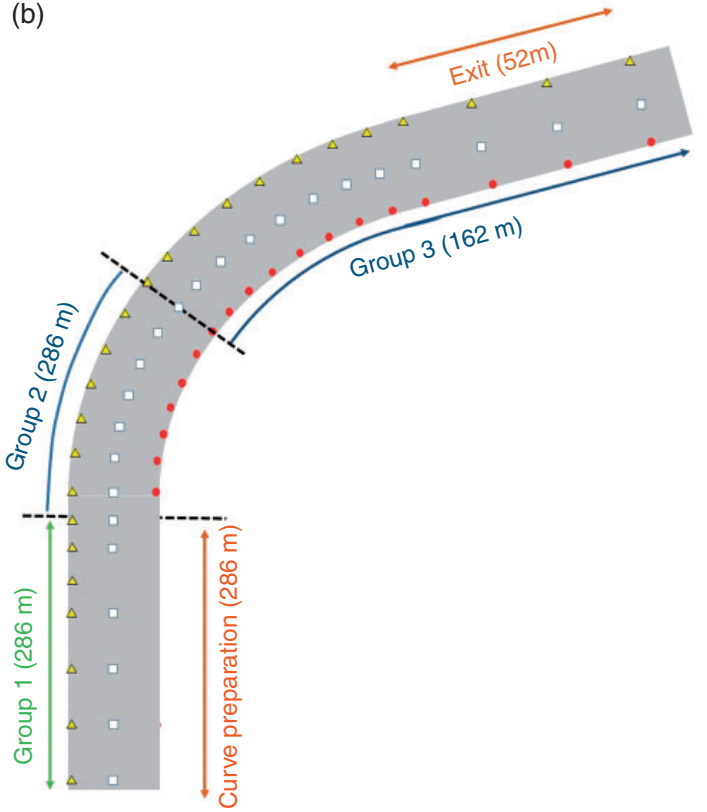

Figure 4 Stud sections for the $150 \mathrm{~m}$ long (left) and $400 \mathrm{~m}$ long (right) curves (not to scale). In both types of curves, the LEDs in groups 1 and 2 switch on at the same time (when the virtual car reaches a distance of $300 \mathrm{~m}$ from section 1). In the $400 \mathrm{~m}$ long curves, those in group 3 switch on as soon as the vehicle reaches the first stud (available in colour in online version)

ratio between minimum and mean luminance). These values are above the European standard for such a rural road $\left(\mathrm{L} \geq 1.00 \mathrm{~cd} / \mathrm{m}^{2}\right.$ and $\left.\mathrm{U}_{0} \geq 0.40\right)$.

\subsection{Procedure}

At the beginning of the experimental sessions, the participants read and signed an informed consent form and filled a questionnaire registering some background details and driving history. They were told they were about to participate in an experiment about driving, which would include driving on a car simulator and filling a questionnaire; they were about to engage in driving a simulated car that was operated the same way as a normal car (with a steering wheel, pedals and so on). They were also told that after a short practice drive during daytime conditions, they would drive on a route under varying night time conditions and that the task required that they drove as they normally would. No speed limit was given, as the driver was expected to guess this limit $(90 \mathrm{~km} / \mathrm{h})$ from the road design and visual environment as specified by the French traffic code (see Figure 3). Then, the participants entered the simulator and familiarized themselves with the simulation through driving on a practice run in daylight conditions. After this, they went through the assessment drives for each of the three driving conditions, separated by brief breaks, and then filled a short questionnaire evaluating their subjective experience. An experimental session lasted about 1 hour.

\section{Results}

Several dependent variables have been considered in the following. First, speed is investigated in Section 3.1. Lateral positioning is first considered in the straight sections 
before the preparatory sections (Section 3.2). Then, in order to make the interpretations easier and more accurate, two series of analyses have been conducted, on the right and left curves (Section 3.3). They address the lateral position in the preparatory and curve sections, the standard deviation of these lateral positions and the crossovers. Finally, the participant's subjective judgments are considered in Section 3.4. Table 1 gives an overview of the main results: mean speed, standard deviation of lateral position and time spent across the line, for each curve section and each illumination condition.

\subsection{Speed}

The analysis of speed in the straight road sections yielded a significant illumination effect $(\mathrm{F}(1.71,453.96)=11.96, \mathrm{p}<0.001)$. Tukey tests showed significant differences between the unlit condition $(\mathrm{M}=98.3 \mathrm{~km} / \mathrm{h})$ and both, the studs $(\mathrm{M}=101.0 \mathrm{~km} / \mathrm{h})$ and luminaires conditions $(\mathrm{M}=101.4 \mathrm{~km} / \mathrm{h})$, but not between the studs and luminaires conditions.
The analysis of the preparatory and curve road sections yielded significant effects of road section in both left and right curves $(\mathrm{F}(1$, $151)=55.71$ and 73.86, respectively, with $\mathrm{p}<0.001$ for both), indicating faster speeds before the curves $(M=99.1$ and $97.8 \mathrm{~km} / \mathrm{h}$ in left and right curves, respectively) than inside the curves $(\mathrm{M}=94.2$ and $92.5 \mathrm{~km} / \mathrm{h}$ in left and right curves, respectively).

In left curves, the effect of illumination approached significance $(\mathrm{F}(1.86,281.30)=$ $2.71, \mathrm{p}=0.07)$, and a road section $\times$ illumination interaction was found $(\mathrm{F}(1.94,292.42)$ $=6.84, \mathrm{p}<0.005)$. Tukey post-hoc tests found no significant differences between the three illumination conditions in the left curves, while in the preparatory sections, the speed was significantly higher in the luminaires conditions compared to both the studs and the unlit conditions.

In right curves, no effect of illumination was found $(F(1.76,265.89)=0.79, p=0.439)$, whereas the interaction only approached significance $(\mathrm{F}(1.96,296.40)=3.03, \mathrm{p}=0.051)$.

Table 1 Main results: mean speed, mean standard deviation (SD) of the lateral position, and mean time spent across the lines (crossovers), for the three illumination conditions

\begin{tabular}{lllrrr}
\hline Variable & Unit & Section & Luminaires & Unlit & Studs \\
\hline Speed & $\mathrm{km} / \mathrm{h}$ & Straight R & $101.5(17.9)$ & $98.1(20.4)$ & $100.6(15.5)$ \\
Speed & $\mathrm{km} / \mathrm{h}$ & Straight L & $101.3(18.6)$ & $98.5(20.4)$ & $101.3(16.1)$ \\
Speed & $\mathrm{km} / \mathrm{h}$ & Preparatory R & $98.4(17.8)$ & $96.8(20.8)$ & $98.2(15.6)$ \\
Speed & $\mathrm{km} / \mathrm{h}$ & Preparatory L & $100.8(20.0)$ & $97.9(22.2)$ & $98.6(18.3)$ \\
Speed & $\mathrm{km} / \mathrm{h}$ & Curve R & $91.8(17.0)$ & $92.5(20.3)$ & $93.3(13.9)$ \\
Speed & $\mathrm{km} / \mathrm{h}$ & Curve L & $94.7(18.9)$ & $94.8(21.4)$ & $93.1(15.6)$ \\
SD lateral & $\mathrm{cm}$ & Straight R & $26.8(12.0)$ & $26.1(16.8)$ & $28.0(19.5)$ \\
SD lateral & $\mathrm{cm}$ & Straight L & $26.0(11.0)$ & $26.3(10.7)$ & $25.2(10.8)$ \\
SD lateral & $\mathrm{cm}$ & Preparatory R & $20.9(12.7)$ & $19.8(10.8)$ & $20.5(11.8)$ \\
SD lateral & $\mathrm{cm}$ & Preparatory L & $21.1(13.2)$ & $20.1(11.2)$ & $17.2(9.8)$ \\
SD lateral & $\mathrm{cm}$ & Curve R & $32.6(12.2)$ & $36.9(18.7)$ & $31.3(16.9)$ \\
SD lateral & $\mathrm{cm}$ & Curve L & $37.2(13.1)$ & $37.3(11.8)$ & $35.9(11.7)$ \\
Crossovers & $\mathrm{seconds}$ & Straight R & $0.67(1.72)$ & $0.81(2.33)$ & $0.57(1.67)$ \\
Crossovers & $\mathrm{seconds}$ & Straight L & $0.73(1.62)$ & $0.72(1.84)$ & $0.86(1.94)$ \\
Crossovers & seconds & Preparatory R & $0.26(0.94)$ & $0.26(1.08)$ & $0.18(0.69)$ \\
Crossovers & seconds & Preparatory L & $0.39(1.15)$ & $0.30(1.90)$ & $0.31(1.04)$ \\
Crossovers & seconds & Curve R & $1.66(2.26)$ & $2.02(2.52)$ & $1.15(1.82)$ \\
Crossovers & seconds & Curve L & $0.80(1.53)$ & $1.00(1.52)$ & $0.98(1.83)$ \\
\hline
\end{tabular}

Note: Speed is in $\mathrm{km} / \mathrm{h}$, while the SD of the lateral position is in centimetres and the durations in seconds. Data for Left (L) and Right (R) curves are given separately (standard deviations are in brackets). 


\subsection{Lane positioning: straight sections}

On the straight sections before the preparatory section, the analysis of the lateral positioning yielded a significant effect of illumination $(\mathrm{F}(2,530)=6.65, \mathrm{p}<0.005)$, with Tukey tests confirming significant differences between the unlit condition and both the studs and the luminaires conditions, whereas the difference between the studs and the luminaires conditions was not significant. The participants drove the virtual car with its axis positioned on average $11.6 \mathrm{~cm}$ to the right of the lane axis in the unlit condition, compared to $7.7 \mathrm{~cm}$ in the studs condition and $5.8 \mathrm{~cm}$ in the luminaires condition. The analysis of the standard deviations of the lateral positions found no significant illumination effect in these straight sections $(\mathrm{F}(1.95$, $516.68)=0.01, \mathrm{p}=0.987)$.

\subsection{Lane positioning: Preparatory sections and curves}

For each curve geometry (length and direction), the mean trajectories were almost the same whatever the illumination condition. However, trajectories in left and right turns were found to be different, which led us to investigate them separately.

\subsubsection{Right turns}

Lateral position. The analysis yielded a significant road section effect $(\mathrm{F}(1$, $151)=24.85, \mathrm{p}<0.001)$, with the participants driving the virtual car with its centre-line positioned on average $6.9 \mathrm{~cm}$ to the right of the lane centre in the preparatory section, and $4.3 \mathrm{~cm}$ to the left of the lane centre inside the curve.

The illumination effect was also significant $(\mathrm{F}(2.00,301.60)=17.84, \mathrm{p}<0.001)$. Tukey post hoc tests confirmed that the differences between the mean lateral position in the luminaires, unlit and studs conditions $(4.6 \mathrm{~cm}$ to the left, 0.9 and $7.5 \mathrm{~cm}$ to the right of the lane centre, respectively for the three conditions) were all significant. No interaction was found $(\mathrm{F}(1.88,284.41)=$ $2.20, \mathrm{p}=0.116)$.

Standard deviation of the lateral position. Table 2 shows the SDs of the lateral positioning in right turns, for the six sub-conditions created by the road section $\times$ illumination design. For these right turns, the analysis revealed a significant effect of road section $(\mathrm{F}(1,151)=143.87, \quad \mathrm{p}<0.05), \quad$ indicating larger SDs inside the curves $(\mathrm{M}=33.6 \mathrm{~cm})$, as compared to the preparatory sections $(\mathrm{M}=20.4 \mathrm{~cm})$. The illumination effect was also significant $(\mathrm{F}(1.96, \quad 297.22)=3.32$, $\mathrm{p}<0.005)$. Tukey post-hoc tests found a significant difference between the studs $(\mathrm{M}=25.9 \mathrm{~cm})$ and the unlit conditions $(\mathrm{M}=28.4 \mathrm{~cm})$, not between the luminaires $(\mathrm{M}=26.7 \mathrm{~cm})$ and the two other conditions.

The interaction was found to be significant $(\mathrm{F}(1.87, \quad 280.97)=6.92, \quad \mathrm{p}<0.005) ; \quad$ Tukey tests found no difference across illumination conditions in the preparatory sections, while in curves, the lateral SD was found significantly higher in the unlit condition $(\mathrm{M}=$ $36.9 \mathrm{~cm})$ compared to both the luminaires $(\mathrm{M}=32.6 \mathrm{~cm})$ and the studs conditions $(\mathrm{M}=31.3 \mathrm{~cm})$.

Crossovers. Table 3 shows the mean time spent across the nearside edge-line and across the centre-line in right turns, for the six subconditions (road section $\times$ illumination). Adding crossovers on the centre-line and nearside edge-line gives an index of the risk

Table 2 Mean standard deviation (SD) of the lateral position in right turns, in centimetres, for the three illumination conditions

\begin{tabular}{llll}
\hline Section & Unlit $(\mathrm{cm})$ & Luminaires $(\mathrm{cm})$ & Studs $(\mathrm{cm})$ \\
\hline Preparatory & $19.8(10.8)$ & $20.9(12.7)$ & $20.5(11.8)$ \\
Curve & $36.9(18.7)$ & $32.6(12.2)$ & $31.3(16.9)$ \\
\hline
\end{tabular}


Table 3 Mean time (seconds) spent across the nearside road edge-line and the centre-line in the preparatory and curved sections in right turns, for the three illumination conditions

\begin{tabular}{lllll}
\hline Road side & Section & Unlit $(\mathrm{cm})$ & Luminaires $(\mathrm{cm})$ & Studs $(\mathrm{cm})$ \\
\hline Nearside edge-line & Preparatory & $0.22(1.06)$ & $0.25(0.93)$ & $0.14(0.65)$ \\
Centre-line & Preparatory & $0.03(0.24)$ & $0.01(0.12)$ & $0.04(0.26)$ \\
Nearside edge-line & Curve & $1.95(2.53)$ & $1.55(2.28)$ & $1.11(1.79)$ \\
Centre-line & Curve & $0.07(0.30)$ & $0.10(0.42)$ & $0.05(0.23)$ \\
Both & Preparatory & $0.26(1.08)$ & $0.26(0.94)$ & $0.18(0.69)$ \\
Both & Curve & $2.02(2.52)$ & $1.66(2.26)$ & $1.15(1.82)$ \\
\hline
\end{tabular}

exposure due to a lack of control of the vehicle trajectory.

The raw data suggest safer behaviour in right curves in the studs condition, with a mean crossover of $0.63 \mathrm{~s}$, compared to 0.86 and $1.03 \mathrm{~s}$ in the luminaires and unlit conditions, respectively. It was not possible, however, to perform repeated measures ANOVAs on the crossovers data, because crossovers are sparse events: a crossover was recorded in $22.04 \%$ of the straight sections, $12.06 \%$ of the preparatory sections and $60.31 \%$ of the curve sections, which means that only $31.47 \%$ of all these crossover data are non-zero $(39.69 \%$ in curves). Thus, sphericity and normality were not reached, and usual data transforms such as the Greenhouse-Geisser correction did not permit an ANOVA either (see the SD in Table 3). This is why non-parametric tests were conducted instead.

A Friedman test was conducted on the crossovers duration, and a Cochran test on the number of crossovers. The Friedman test shows a significant effect of the illumination $(\mathrm{Q}(2)=46.70, \mathrm{p}<0.0001)$ on the crossover duration ranking. Nemenyi pair comparisons show significant differences for all three conditions, meaning that the studs condition is safer than the luminaires condition, which is turn is safer than the unlit condition, with respect to crossover durations in right turns.

The Cochran test also shows a significant effect of illumination $(\mathrm{Q}(2)=18.392$, $p<0.0001)$ on the number of crossovers. Bonferroni pair comparisons show a significant difference between the studs and unlit conditions $(p<0.001)$, meaning that the studs condition is safer with respect to the number of crossovers in right turns. The other pair comparisons were not found to be significant.

One may wish to compare the mean time spent across the lines to the mean time spent to go through the curves. From the mean speed in curves and preparatory sections respectively, it appears that short turns (150$\mathrm{m}$ long) take $5.72 \mathrm{~s}$ to go through, while long curves (400-m long) take $15.25 \mathrm{~s}$. It takes $10.46 \mathrm{~s}$ to go through the $286-\mathrm{m}$ long preparatory sections

\subsubsection{Left turns}

Lateral position. In left turns, the analysis yielded significant effects of road section $(\mathrm{F}(1$, $151)=123.76, p<0.001)$, with the participants driving the virtual car with its axis positioned $11.1 \mathrm{~cm}$ to the right of the lane centre in the preparatory section and $35.2 \mathrm{~cm}$ to the right inside the curves. The illumination effect was also significant $(\mathrm{F}(1.99$, $300.72)=7.82, p<0.001)$. The participants drove the virtual car approximately 19.6, 21.8 and $28.0 \mathrm{~cm}$ to the right of the lane centre, respectively, in the luminaires, in the studs and in the unlit conditions; Tukey tests found significant differences between the unlit and the other two illumination conditions, but not between the studs and the luminaires 
conditions. The interaction was not significant, $\mathrm{F}(1.92,289.36)=2.38, \mathrm{p}=0.096$.

Standard deviation of the lateral position. The analysis on the SD of the vehicle's lateral position in left turns (Table 4) revealed a significant effect of the road section $(\mathrm{F}(1$, $151)=366.3, \mathrm{p}<0.001)$ with larger SDs inside the curves $(\mathrm{M}=36.8 \mathrm{~cm})$, as compared to the curve preparation section $(\mathrm{M}=19.5 \mathrm{~cm})$. An effect of the illumination was found $(\mathrm{F}(2.00$, $301.84)=5.302, \mathrm{p}<0.01)$; Tukey tests found the lateral SD significantly lower in the studs condition $(\mathrm{M}=26.6 \mathrm{~cm})$ as compared to the other two illumination conditions, while the difference between the unlit $(\mathrm{M}=28.7 \mathrm{~cm})$ and the luminaires conditions $(M=29.2 \mathrm{~cm})$ was not significant. No interaction was found $(\mathrm{F}(1.92,290.07)=1.149, \mathrm{p}=0.317)$.

Crossovers. In left turns, the raw data of the mean crossover durations suggest safer behaviour in the unlit and studs conditions in the curve preparation sections, when compared to the luminaires condition, and conversely a safer behaviour in curves in the luminaires condition (see Table 5). A repeated

Table 4 Mean standard deviation (SD) of the lateral position in left turns, in centimetres, for the three illumination conditions

\begin{tabular}{llll}
\hline Section & Unlit $(\mathrm{cm})$ & Luminaires $(\mathrm{cm})$ & Studs $(\mathrm{cm})$ \\
\hline Preparatory & $20.1(11.2)$ & $21.1(13.2)$ & $17.2(9.8)$ \\
Curve & $37.3(11.8)$ & $37.2(13.1)$ & $35.9(11.7)$ \\
\hline
\end{tabular}

measures ANOVA was not possible either, so non-parametric (Friedman and Cochran) tests have been conducted. The Friedman test shows a significant effect of illumination $(\mathrm{Q}(2)=7.907, \mathrm{p}=0.019)$ on the crossover duration ranking. However, Nemenyi pair comparisons did not show any significant differences across conditions. The Cochran test also shows a significant effect of illumination $(\mathrm{Q}(2)=16.044, \quad \mathrm{p}<0.0001)$ on the number of crossovers. Bonferroni pair comparisons show significant differences between the studs and the unlit conditions, and between the luminaires and the unlit conditions $(\mathrm{p}<0.01)$, but not between the studs and the luminaires conditions, meaning that both the studs and the luminaires conditions are safer than the unlit condition, with respect to the number of crossovers in left turns.

\subsection{Subjective assessment}

The experimental conditions were rated on three seven-point scales, ranging from very unsafe to very safe, from very uncomfortable to very comfortable and from allowing poor vehicle control to excellent vehicle control. A repeated measures ANOVA was conducted on these ratings: the participants rated both the studs and the luminaires conditions as safer compared to the unlit condition $(\mathrm{Ms}=5.39,5.78$ and 3.44, respectively), more comfortable $(\mathrm{Ms}=5.45,5.89$ and 3.28) and allowing better control $(\mathrm{Ms}=5.39,5.56$ and 4.00) as compared to the unlit condition

Table 5 Mean time (seconds) spent across the nearside road edge-line and the centre-line in the preparatory and curved sections in left turns, for the three illumination conditions

\begin{tabular}{lllll}
\hline Road side & Section & Unlit $(\mathrm{cm})$ & Luminaires $(\mathrm{cm})$ & Studs $(\mathrm{cm})$ \\
\hline Nearside edge-line & Preparatory & $0.20(0.79)$ & $0.29(1.10)$ & $0.27(0.95)$ \\
Centre-line & Preparatory & $0.11(0.49)$ & $0.10(0.40)$ & $0.04(0.43)$ \\
Nearside edge-line & Curve & $0.38(0.95)$ & $0.12(0.45)$ & $0.55(1.48)$ \\
Centre-line & Curve & $0.62(1.25)$ & $0.67(1.51)$ & $0.43(1.22)$ \\
Both & Preparatory & $0.30(1.90)$ & $0.39(1.15)$ & $0.31(1.04)$ \\
Both & Curve & $1.00(1.52)$ & $0.80(1.53)$ & $0.98(1.83)$ \\
\hline
\end{tabular}


$(\mathrm{F}(2,34)=17.37,20.45$ and 11.43 respectively, all $\mathrm{p}<0.001)$.

\section{Discussion}

This study compared driver performance measures in a driving simulator in the presence of an ALD application, to performance on an unlit road and with typical road luminaires.

An increase in speed increases the stopping distance, and thus the collision risk. The risk can be computed with standard models, such as the Nilsson rule. On rural roads such as the one which is simulated here, for instance, a decrease of $3 \mathrm{~km} / \mathrm{h}$ at $90 \mathrm{~km} / \mathrm{h}$ leads to a decrease of $5.9 \%$ of accidents with injuries and $11.5 \%$ for accidents with fatalities. Besides, an increase in speed increases the severity of an accident, in terms of pedestrian fatalities. ${ }^{23,24}$ In the present experiment, the analysis of speed indicated that the participants varied their average speed by about $7 \mathrm{~km} / \mathrm{h}$ between the road sections (see Table 1 ), traveling as can be expected at fastest speeds in the straight road sections further from the curves, slower in the sections preceding the curves and slower yet inside the curves. The participants travelled slightly slower in the unlit condition, as compared to the studs and luminaires conditions, but only in the straight sections. The studs and the luminaires were already visible $300 \mathrm{~m}$ ahead of their position, hence, when the virtual car was still well within the straight sections; this might help to explain the small differences in speed between the illumination conditions. Inside the preparatory sections leading to left curves, the luminaires condition induced slightly faster speeds, as compared to both the unlit and studs conditions, while in these same sections, there were no significant differences in speed between the unlit and studs conditions. This suggests that at least with respect to speed, studding the approach to (left) curves may be advantageous compared to road lighting, partly via the reduction in the distance between studs at the approach to the curve, which might have affected how the participants perceived their own speeds. Future research would need to directly target this question, but it is also noteworthy that the studs condition appeared to have produced substantially lower speed variances, as compared to the other conditions, which is yet another advantage to be taken into consideration. $^{25}$

The analysis of lateral position showed that in all illumination conditions the participants drove near the centre of their lane - the mean distance is lower than $11 \mathrm{~cm}$ from the lane centre - except in left curves, where the lateral position may be quite far from the lane centre, up to $28 \mathrm{~cm}$ in the unlit condition. In these left curves, the lateral position in the unlit condition was found more to the right than in the two other illumination conditions. Interestingly, in all road sections, the mean lateral position was found, in the studs condition, between the lateral position in the luminaires condition (to the left) and in the unlit condition (more to the right). While the reason for this behaviour is unclear, it may be seen as a careful strategy.

Vehicle control was assessed with two complementary variables, the standard deviation of the lateral position and the crossovers, either in terms of duration or in terms of number of crossovers. With respect to the unlit condition, the studs' condition was found significantly better in all comparisons, except the crossover duration in left turns, where the difference was not significant. The analyses also suggest a benefit of the studs with respect to the luminaires condition, with shorter crossovers in right turns in the studs condition, as well as smaller standard deviation of the lateral position in left curves. This is consistent with our hypotheses, and should now lead to fine tuning of the design of ALD applications, as well as road experiments. 


\subsection{Future directions}

This study evaluated an exploratory design prototype for an ALD signalling application: LED-based road studs in the curves of winding roads, switched on to outline the lane edges for approaching vehicles entering their detection zone. It is an important step forward in direction of designing a smart ALD application for country roads. However, this experiment consisted of a very simple driving environment. The studs, relative to the luminaires, have improved driver performance, but there is no doubt luminaires would have been more effective in illuminating obscured road obstacles, cyclists along the side of the road, and so forth. It is not unlikely that if such targets were to be included in the drive, the greater effectiveness of the luminaires in illuminating these road hazards would have balanced the relative benefits of the road studs: target detection would mainly depend on the vehicle's headlamps. ${ }^{26}$

In the proposed ALD application, the studs are switched on and off depending on the incoming traffic, mainly for energy saving. Care must be taken, then, to the traffic preceding the participant, which would trigger the application. This was not considered in the present study, and might appear to some drivers as random chunks of lights appearing and disappearing. Various unpredicted illumination patterns could also result from system failures, which is why on a practical level, control units that allow authorities to monitor, to repair and to deactivate the application in case of malfunction should be considered mandatory. Studs, triggered in response to traffic approaching from one direction would naturally also become visible in the mirrors of vehicles travelling in the opposite direction, potentially masking traffic approaching from behind, with intention to overtake.

In this regard, there are pros and cons that are associated with each design and that are further dependent on the type of road on which a specific design might be implemented. For example, on single undivided carriageways, where the lane used for overtaking is the same lane used by oncoming traffic, studding the nearside edge, the centre-line of the road and the offside road edge can increase the risk for head-on collisions. More specifically, the studs might mask the headlights of an overtaking vehicle or those of a vehicle approaching in the opposite lane. In these scenarios, there is a risk for delayed identification of vehicle headlights, perhaps more so if the colours of the studs do not allow clear differentiation from vehicle the headlights. If only the nearside road edge or only the central line on an undivided carriageway has studs, some confused drivers might - when entering the studs section accidentally proceed towards the wrong side of the single studs line. Implementation in conjunction with a continuous separation line, that is, a zone where overtaking is not allowed, and with clearly marked central and edge-lines should help reducing these two types of risks.

It is up to future research to systematically compare alternative designs that may be advantageous over the one tested in this study, in producing the safest driving performance measures while eliminating or at least minimizing any undesired adverse effects that might result from any of the causes discussed above. As such, it must first identify the conditions in which the benefits achieved by the studs are outweighed by unintentional adverse effects caused by masking or any other negative information effects and design lighting applications with proven ability to eliminate these problems. Indeed, our results partly depend on the parameters used in the studs' condition, such as intervals between studs, lengths of the different stud sections, colours and so forth.

The contribution of road delineation to road safety is undeniable. There is also 
a strong basis to the assertion that although passive, that is, retro-reflective studs, coupled with painted line markings are superior, in some situations, to just painted lines in their capability of providing the visual information necessary to delineate road space, they are especially in curves and under conditions of poor visibility - inferior to active, that is, selfluminous road studs in achieving the same goal, ${ }^{8}$ mainly because retro-reflective markings are only visible when in the headlamps beam. Indeed, in the present experiment, the simulated 'unlit' condition provided visual cues very close to what retro-reflective markings would have provided, with poorer behavioural results than active studs.

Active road studs entail lower costs and have some clear environmental benefits as compared to conventional street lighting, such as reduction in energy consumption and waste and light pollution of the sky, as well as an obvious safety benefit by eliminating lighting poles. On these bases, our primary goal was to show that active road studs do not lead to adverse illumination and information effects on driver performance or a disbenefit compared to an unlit road. The studs condition was found superior as compared to both the unlit condition, which induced poorer vehicle control (higher variability of the lateral position, greater lateral vehicle displacement inside the left curves, and more crossovers), and the luminaires condition (which induced greater speeds before the left curves, greater lateral variability before the left curves, and longer crossovers in right turns). Therefore, we can conclude that the ALD application designed, simulated and tested in the present study enhanced the ability of drivers to control the virtual car and to reduce its lateral displacement while minimizing the increment in speed. As such, this study provides a crucial step in the direction of implementing intelligent self-luminous road studs on country roads.

\section{Acknowledgments}

We are grateful to Fabrice Vienne and Nguyen-Thong Dang for creating the simulation, to David Callu and Jacky Robouant for their assistance with this task, to Eric Dumont, Lancelot Six and Abdourahmane Koita, for their contributions to the processing of the simulator data, and to Adrian Cotrus, Jean Iaquinta, Martin Lamb and Paul Brooks for their involvement in the earlier stages of the design of the active lane delineation application tested in this study. Special thanks, again, to Eric Dumont, for his careful reading of the manuscript.

\section{Declaration of Conflicting Interests}

The authors declared no potential conflicts of interest with respect to the research, authorship, and/or publication of this article.

\section{Funding}

The authors disclosed receipt of the following financial support for the research, authorship, and/or publication of this article: This experiment was conducted in the framework of INROADS, a European research and development cooperation project (FP7) devoted to the development of self-powered LED-based road studs.

\section{References}

1 Miller TR. Benefit-cost analysis of lane marking. Transportation Research Record 1992; 1334: 38-45.

2 Moses P. Edge lines and single vehicle accidents. Western Road 1986; April: 8-9.

3 Horberry T, Anderson J, Regan M. The possible safety benefits of enhanced road markings: a driving simulator evaluation. Transportation Research Part F: Traffic Psychology and Behaviour 2006; 9: 77-87. 
4 Charlton SG. Delineation effects in overtaking lane design. Transportation Research Part F: Traffic Psychology and Behaviour 2007; 10: 153-163.

5 Charlton SG. The role of attention in horizontal curves: a comparison of advance warning, delineation, and road marking treatments. Accident Analysis and Prevention 2007; 39: 873-885.

6 Zador P, Stein HS, Wright P, Hall J. Effects of chevrons, post-mounted delineators, and raised pavement markers on driver behaviour at roadway curves. Transportation Research Record 1987; 1114: 1-10.

7 North-Holland Department of Traffic Management and Realization.

Recommendation for use of active marking. Technical Report. Haarlem, Netherlands: Department of Traffic Management and Realization, 2005.

8 Reed N. Driver behaviour in response to actively illuminated road studs: a simulator study. Technical Report, Crowthorne, UK: Transport Research Laboratory, 2006.

9 Shahar A, Brémond R. Toward smart active road studs for lane delineation: Proceedings of Transport Research Arena 2014, Part X, Session STS 51, Paris, France, Apr 14-17: 2014: 1-9.

10 Wanvik PO. Effects of road lighting: an analysis based on Dutch accident statistics 1987-2006. Accident Analysis and Prevention 2009; 41: 123-128.

11 Wang M. Chain-control device for solar road studs and solar energy flash device. US Patent 6,929,378, 2005.

12 US Department for Transport. Road markings. US Dept. for Transport. In: Traffic Signs Manual. Washington, DC: US Department for Transport, 2003.

13 Gibson JJ. The Perception of the Visual World. Boston: Houghton Mifflin, 1950.

14 Argent KR. Transverse pavement markings for speed control and accident reduction. Transportation Research Record 1980; 773: $11-14$.
15 Denton GG. The influence of visual pattern on perceived speed. Perception 1980; 9: 393-402.

16 Drakopoulos A, Vergou G. Evaluation of the converging chevron pavement marking pattern at one Wisconsin location. Technical Report, Washington, DC: American Automobile Association Foundation for Traffic Safety, 2003.

17 Kallberg V. Reflector posts - signs of danger? Transportation Research Record 1993; 1403: 57-66.

18 Wilde GJS. Risk homeostasis theory and traffic accidents: propositions, deductions and discussion of dissension in recent reactions. Ergonomics 1988; 31: 441-468.

19 Shapeley R, Enroth-Cugell C. Visual adaptation and retinal gain control. Progress in Retinal Research 1984; 3: 263-346.

20 Villa C, Brémond R, Saint-Jacques E. Visibility and discomfort glare of LED road studs. Implications for road safety and energy saving. Lighting Research and Technology 2015; 47: 945-963.

21 Lappi O. Future path and tangent point models in the visual control of locomotion in curve driving. Journal of Vision 2014; 12: 1-22.

22 European Committee for Standardization. European Standard 13201-2: Road Lighting. Part 2: Performance Requirements. Brussels: CEN, 2003.

23 Rosen E, Stigson H, Sander U. Literature review of pedestrian fatality risk as a function of car impact speed. Accident Analysis and Prevention 2011; 43: 25-33.

24 Kroyer H, Jonsson T, Varhelyia A. Relative fatality risk curve to describe the effect of change in the impact speed on fatality risk of pedestrians struck by a motor vehicle. Accident Analysis and Prevention 2013; 62: 143-152.

25 Aarts L, van Schagen I. Driving speed and the risk of road crashes: a review. Accident Analysis and Prevention 2006; 38: 215-224.

26 Brémond R, Bodard V, Dumont E, NouaillesMayeur A. Target visibility level and detection distance on a driving simulator. Lighting Research and Technology 2013; 45: 76-89. 